\title{
A TEORIA DAS REPRESENTAÇÕES SOCIAS NOS ESTUDOS AMBIENTAIS
}

\section{The theory of social representations in environmental studies}

\author{
Beatriz FAGUNDES ${ }^{1}$
}

\section{RESUMO}

Este artigo tem por finalidade apresentar uma reflexão sobre a Teoria das Representações Sociais, criada por Moscovici, como forma de contribuir com sua incorporação na abordagem da geografia socioambiental. Para tanto, o artigo recupera o processo de constituição e os desdobramentos da Teoria das Representações Sociais; apresenta como são construídas as representações pelas pessoas na vida cotidiana; e aponta algumas possíveis reflexões sobre a temática ambiental, a partir desta teoria.

Palavras-chave: Teoria das Representações Sociais; Geografia; Meio Ambiente.

\begin{abstract}
This article aims at presenting a reflection about the Theory of Social Representations, created by Moscovici, so as to contribute with its incorporation to the socio-environmental geography. For in such a way, the article recoups the process of constitution and the unfoldings of the Theory of the Social Representations; it presents as the representations for people in their daily lives; and some possible reflections on thematic environmental, from this theory.
\end{abstract}

Keywords: Theory of Social Representations; Geography; Environment. 


\section{INTRODUÇÃO}

No campo da Geografia, a abordagem "socioambiental", tal como proposta por Mendonça (2002), tem salientado a necessidade de superar enfoques dicotômicos que consideram, de um lado, o ambiente, como sinônimo de natureza, e de outro a sociedade, rumo a um enfoque mais integrador.

No mesmo sentido, Fèlonneau (2003) reclama no "campo ambiental" uma abordagem que ultrapasse a dicotomia sujeito/objeto, objetivo/subjetivo, que marcou muitos estudos. Para a autora, o enfoque das representações sócioespaciais seria um caminho profícuo para realizar esta integração, pois, baseando-se em Stokols ${ }^{2}$ (1982), Fèlonneau (2003, p. 146), afirma que

o ambiente físico é um composto de aspectos materiais e simbólicos, cuja análise integra elementos subjetivos e objetivos. São os ocupantes dos diversos quadros espaciais que transformam um conjunto de elementos materiais, em um espaço simbolicamente significativo (Tradução nossa).

Nesse sentido, a abordagem das representações sociais torna-se um caminho frutífero para uma "geografia socioambiental" (MENDONÇA, 2002), que busca a indissociabilidade entre o natural e o social, o material e o simbólico.

Também complementa Mendonça (2002, p. 121) que é preciso considerar que

os problemas ambientais são, fundamentalmente, problemas do conhecimento. [...] Apreender a complexidade ambiental não constitui um problema de aprendizagens do meio, e sim de compreensão do conhecimento sobre o meio.

$\mathrm{E}$, nesse mesmo sentido, considerar o conhecimento do senso comum (que é outra definição para representação social), também é de extrema importância, para compreendermos as atitudes e valores em relação à natureza.

Para Moscovici (2003) todas as nossas reflexões e comunicações são reproduzidas em representações.
A partir delas, podemos ter uma reflexão mais concreta sobre as experiências cotidianas, ou o saber do senso comum. Deste modo, a Teoria das Representações Sociais, proposta por Moscovici (1978; 2003), procura entender esse conhecimento popular, ou seja, as representações sociais criadas pelos indivíduos ou pela coletividade. No entanto, Sá (1998) adverte que as representações sociais não se reduzem a todo e qualquer conhecimento e sim, segundo Jodelet (2001, p. 22), a "uma forma de conhecimento, socialmente elaborada e partilhada, com um objetivo prático, e que contribui para a construção de uma realidade".

Assim, quando as pessoas, na sua vida cotidiana, deparam-se com questões e/ou fenômenos de natureza ambiental, elaboram coletivamente um saber que permite conduzir a vida prática. De forma que, conhecer este saber, seguindo a recomendação de Leff (2001 apud MENDONÇA, 2002), contribuiria muito para a compreensão dos problemas ambientais contemporâneos.

Contudo, apropriar-se desta teoria das representações sociais, no campo da Geografia, não é tarefa fácil e requer toda uma leitura, não só das obras de Moscovici, mas também de seus colaboradores e continuadores, para que não tomemos por representação social qualquer forma de conhecimento, mas tão somente aquela que de fato é uma representação social, tal como nos adverte Sá (1998).

Nesse sentido, propomos aqui expor um pouco mais dessa teoria. Num primeiro momento, traremos as contribuições de estudiosos que inspiraram Moscovici, na sua formação, e uma abordagem da teoria de Moscovici e de seus continuadores. Num segundo momento, mostraremos como as pessoas comuns constroem representações sociais sobre determinados fenômenos. Assim, esperamos poder contribuir para o aprofundamento da teoria das representações sociais nos estudos geográficos, principalmente, no campo ambiental.

\section{A TEORIA DAS REPRESENTAÇÕES SOCIAIS}

A teoria das representações sociais foi incorporada, na Geografia, primeiramente, pela Geografia Cultural. Esta tendência tematiza, a partir dos anos de

2 STOKOLS, D. People in place: a transactional view of settings. In: HARVEY, J (Ed.). Cognition, Social Behavior ant The environment. Hillsdale, Lawrence Erlbaum, 1982. 
1960, questões da subjetividade e da representação do espaço, entre outros elementos geográficos. Assim, tanto o conhecimento científico como os saberes populares são perspectivas intersubjetivas, embutidas em linguagens diferenciadas, que nos parecem evidentes como objetos da Geografia Cultural. Portanto, falar de representações sociais para a construção de uma abordagem socioambiental indica uma aproximação entre os campos cultural e ambiental da Geografia.

A Teoria das Representações Sociais ficou conhecida em 1961, através da obra La Psychanalyse: son image e son public desenvolvida pelo psicólogo social francês Serge Moscovici ${ }^{3}$. Nessa época, abordagens linguísticas e semióticas tornaram-se mais importantes nas pesquisas das relações sociais, até que formaram o denominado linguistic turn, o qual destacou o significado como elemento fundamental da compreensão do mundo. Essa abordagem tinha, principalmente, como enfoque, a psicanálise e procurava analisar cientificamente sua repercussão na formação das individualidades e coletividades comuns da época.

Atualmente, a Teoria das Representações Sociais vem sendo cada vez mais empregada em trabalhos das Ciências Sociais, principalmente naqueles de caráter sociológico, antropológico, geográfico e histórico (história das mentalidades), com um enfoque interpretativo e social. O principal emprego da teoria tem sido com vistas a relacionar o saber comum (senso comum) com o conhecimento científico e outras formas de representações.

É importante enfatizar que "a análise das representações pertence a uma tradição que pesquisa a popularização da ciência desde os anos 60" (BAUER, 1995 , p. 229-230). Isto foi, principalmente, o caso da psicanálise, objeto de estudo de Moscovici, cuja popularização fez com que a relação do indivíduo com o seu subconsciente (seja individual ou social) foi discutida em toda amplitude, quase como um campo "em moda".
Moscovici sempre foi contrário a uma definição explícita das representações sociais, para possibilitar que elas fossem trabalhadas percorrendo diversos caminhos, tornando a teoria dinâmica e em constante processo de construção. Por isso, Jodelet ${ }^{4}$ (apud SÁ, 1998, p. 62) aponta as representações sociais se referindo como uma "terra de ninguém". A autora através desta expressão procura mostrar que há "espaço" dentro da teoria, porque as várias perspectivas de estudo, desenvolvem cada uma por si só, também uma espacialidade, ou melhor, uma "terra" da qual todos podem usufruir e acrescentar novas experiências.

Autores mais recentes, contudo, procuraram dar maior precisão ao termo e, para isso, contaram com a liberdade conferida pelo seu próprio idealizador. Assim, segundo Sá (1998, p. 68), a representação social é "uma modalidade de saber gerada através da comunicação na vida cotidiana, com a finalidade prática de orientar os comportamentos em situações sociais concretas" em que o estranho é incorporado.

Wagner ${ }^{5}$, por sua vez, conforme apontado por Freitas (2006), indicou três campos de pesquisa das representações sociais.

O primeiro campo de estudo se refere à pesquisa pioneira de Moscovici, aponta o conhecimento popular das ideias científicas socializadas.

$O$ segundo campo se refere às representações de objetos culturalmente construídos ao longo da história e seus equivalentes modernos.

O terceiro campo está voltado às representações de condições e eventos sociais e políticos que se tornam significantes num curto prazo para a vida social.

Como se percebe, o conceito de representações sociais permite ângulos diferenciados e, assim, também procuramos apresentar não um conceito definido, mas em transformação, com base nas contribuições de di-

3 Originalmente romeno naturalizado francês, a sua obra La Psychanalyse: son image e son public, é um estudo sobre a representação social da psicanálise. Com esta publicação, Moscovici, propôs na época uma nova ideia, ou conhecimento científico, penetrando tanto a esfera pública, como o pensamento popular na França. Fez suas indagações para sair da esfera das ideias para ingressar no ambiente da vida, nos pensamentos, condutas, costumes e no universo das conversações de um grande número de indivíduos. A sua obra foi publicada, primeiramente, na França em 1961, com segunda edição, bastante revisada em 1976 (MOSCOVICl, 1978; 2003). No Brasil foi publicada em 1978, pela Editora Zahar, com o título A Representação Social da Psicanálise.

4 JODELET, D. Représentation sociale: phénomènes, concept et théorie. In: S. MOSCOVICI (Org.). Psychologie Sociale. Paris: PUF; 1984. p. 357-378.

5 WAGNER, W. Sociogênese e características das representações sociais. In: MOREIRAA. S. P.; OLIVEIRA, D. C., (Orgs.). Estudos interdisciplinares de representação social. Goiânia: AB; 1998. p. 03-25.

6 Farr (1995), principal divulgador da perspectiva renovadora de Moscovici na comunidade científica de língua inglesa; Félonneau (2003); Gil Filho (2005); Guareschi (1995); Jodelet (2001; 2005); principal colaboradora e continuadora do trabalho de Moscovici, considerada uma das maiores responsáveis pelo aprofundamento dessa teoria; Jovchelovitch (2000); Lane (1995); Sá (1995; 1998); Sawaia (1995); Spink (1995); Arruda (1995), psicóloga que primeiro trouxe a teoria para o Brasil.

7 As obras de Moscovici são consideradas o epicentro dos estudos sobre representações sociais. 
versos autores ${ }^{6}$, inclusive do próprio Moscovici (1978; 2003) ${ }^{7}$. Dessa maneira

[...] as Representações Sociais se apresentam como a gama de todas as formas de conhecimento, ligado a imagens, conceitos, categorias e teorias, elaborados por indivíduos que pensam a partir do senso comum, "não sozinhos", embutidos em processos de comunicação no cotidiano das relações sociais. Estes conhecimentos não se reduzem apenas aos elementos cognitivos, mas que, compartilhados, contribuem para a construção de uma realidade comum. Assim, as Representações Sociais constituem-se em um fenômeno social que têm de ser entendido a partir do seu contexto de produção, do interagir, isto é, a partir das funções simbólicas e ideológicas a que servem e das formas de comunicação onde circulam (FAGUNDES, 2006, não paginado).

Sob esta perspectiva, verificamos que o conceito de representação social não é preciso, assim permite teorizar o desafio de hermenêuticas múltiplas. Por isso, a teoria transita entre e atinge lateralmente uma série de conceitos sociológicos e psicológicos a ela relacionados, como veremos adiante.

\section{FUNDAMENTOS DA TEORIA DAS REPRESENTAÇÕES SOCIAIS}

A Teoria das Representações Sociais tem sua origem histórica na Sociologia e na Antropologia clássicas, primeiramente proposto por Émile Durkheim e Lucien Lévy-Bruhl. Também apresenta elementos da Teoria da Linguagem de Ferdinand de Saussure, da Teoria das Representações Infantis de Jean Piaget e da Teoria do Desenvolvimento Cultural de Liev Vygotsky (MOSCOVICI, 2003; ALEXANDRE, 2004).

Lévy-Bruhl, um dos mais destacados precursores da teoria das representações sociais, apontou para o fato de que as visões do mundo que se expressam no cotidiano podem ser diferentes. Dedicou os seus estudos à investigação do pensamento, principalmente das pessoas leigas, e da vida cotidiana. Segundo Moscovici (2003, p. 332), "Lévy-Bruhl [...] mostrou que as pessoas não são necessariamente cientistas despreparados, mas podem ser bons místicos ou filósofos da vida cotidiana".

As hipóteses e o enfoque de Lévy-Bruhl foram os catalisadores das teorias iniciais de Piaget e Vygotsky.
A representação do mundo da criança foi estudada por Piaget, do mesmo modo que Moscovici tentou estudar o senso comum dos adultos. Mas, enquanto a Psicologia do Desenvolvimento de Piaget estava interessada na transformação das representações espontâneas em representações científicas e racionais, no curso da vida da criança, Moscovici procurou fazer o inverso, isto é, estudar como representações científicas são transformadas em representações comuns, na vida cotidiana dos adultos.

Em relação à Vygotsky, o que Piaget explorou em escala individual, entre as crianças, o autor russo procurou explorar em escala coletiva, sendo a preocupação com o social uma característica da sua Psicologia. A intenção de Vygotsky era compreender as transformações psicológicas que ocorriam em uma população ligada a sua religião e vivendo de um modo tradicional, mas que passava por uma profunda metamorfose no plano social e cultural (MOSCOVICI, 2003). Dessa maneira, todos estes autores se preocupavam com a formação da imagem conceitual da representação social.

Quanto ao linguista suíço Ferdinand de Saussure, sua ligação com a teoria das representações sociais se dá através do seu estudo sobre a estrutura da linguagem, como um sistema. Sob essa premissa, Moscovici (1978, p. 15) destaca que Saussure partiu da ideia de que toda "língua é um sistema de signos que exprimem ideias, e é comparável, por isso, à escrita, ao alfabeto dos surdos-mudos, aos ritos simbólicos, às formas de polidez, aos sinais militares, etc." As contribuições de Saussure se tornaram bastante relevantes para o desvendamento da comunicação e expressão das representações sociais. Nessa perspectiva, não há comunicação sem que partilhemos determinadas representações e uma representação só será compartilhada se ela for objeto de interesse de comunicação. Assim, a "comunicação é parte do estudo das representações, porque as representações são geradas nesse processo de comunicação e depois, claro, são expressas através da linguagem" (MOSCOVICI, 2003, p. 373).

Em outras palavras, as representações sociais entram no mundo cotidiano em que habitamos e discutimos com nossos amigos e colegas. Elas circulam pelos meios de comunicação e, assim, elas passam a fazer parte de nossas vidas cotidianas, servindo como o principal meio para estabelecer associações e relações sociais, pelas quais nos ligamos uns aos outros (MOSCOVICl, 2003).

Durkheim, por sua vez, oferece inspiração para a ideia de que a representação é coletiva, tanto por sua construção, quanto por sua natureza. Ele inspirou Moscovici na criação do termo "Representações Sociais". 
Alexandre (2004, p. 130) argumenta, em relação à teoria de Durkheim, que "as categorias básicas do pensamento teriam origem na sociedade, e que o conhecimento só poderia ser encontrado na experiência social, ou seja, a vida social seria a condição de todo pensamento organizado e vice-versa".

O esforço para estabelecer a Sociologia, como uma ciência autônoma, levou Durkheim a defender uma separação radical entre representações individuais e coletivas $^{8}$. O sociólogo francês formulou suas ideias, discordando da Psicologia, que procura explicar um fenômeno social através de um fenômeno psicológico. Inicialmente, o objetivo de Durkheim foi sugerir que as representações individuais deveriam ser do campo da Psicologia (individual), enquanto que as representações coletivas formariam o objeto da Sociologia. Tal divisão procurava dar conta de um todo, mas se fundamentava em uma concepção, segundo a qual, as regras que comandam a vida individual não seriam as mesmas que regem a vida coletiva (MOSCOVICl, 2003).

De acordo com Alexandre (2004), Durkheim estudava a religião, a magia e o pensamento mítico, ou seja, representações duradouras, tradicionais, ligadas à cultura. Como bom sociólogo, contextualizou estas representações nas experiências individuais e em tudo que uma sociedade acumula de sabedoria e ciência, com o passar do tempo, e o que é transmitido, lentamente, através das gerações. Por isso, descobriu que estes fenômenos são completamente coletivos, porque são produtos da identidade de uma comunidade. Assim, uma língua, uma religião, um sistema de pensamento (como a ciência), não podem ser inventados por um indivíduo, mas sim criados a partir da interação entre indivíduos.

Ao contrário de Durkheim, Moscovici está interessado na sociedade moderna, na qual a ciência e o pensamento tecnológico tornaram-se onipresentes, de forma que sistemas coletivos entram na construção da vida cotidiana, forçando "[...] as mudanças que as ciências oficiais, religiões, e ideologias, devem passar a fim de penetrar na vida cotidiana e se tornar parte da realidade comum" (SÁ, 1995, p. 22), ou seja, transmutarem-se em representações sociais.

Para enfatizar a distinção entre sociedade primitiva e a atual, Moscovici usa o termo "social", em vez de "coletivo", como forma de diferenciar-se do próprio Durkheim, que empregava justamente o termo represen- tações coletivas. Moscovici afirma ter desejado, apenas, com o termo social, realçar a ideia de diferenciação, de redes de pessoas e suas interações e, ao mesmo tempo, romper com as associações que o termo coletivo tinha herdado do passado. Nas suas próprias palavras:

\begin{abstract}
As representações que me interessam não são nem as das sociedades primitivas, nem as suas sobreviventes, no subsolo de nossa cultura, dos tempos prehistóricos. Elas são as de nossa sociedade atual, de nosso solo político, científico, humano, que nem sempre têm tempo suficiente para se sedimentar completamente para se tornarem tradições imutáveis. E sua importância continua a crescer, em proporção direta com a heterogeneidade e a flutuação dos sistemas unificadores - as ciências, religiões e ideologias oficiais - e com as mudanças que elas devem sofrer para penetrar a vida cotidiana e se tornar parte da realidade comum. Os meios de comunicação de massa aceleraram essa tendência, multiplicaram tais mudanças e aumentaram a necessidade de um elo entre, de uma parte, nossas ciências e crenças gerais puramente abstratas e, de outra parte, nossas atividades concretas como indivíduos sociais. [...] existe uma necessidade contínua de re-constituir o senso comum, [...] nossas coletividades hoje não poderiam funcionar se não se criassem representações sociais, baseadas no tronco das teorias e ideologias que elas transformam em realidades compartilhadas, relacionadas com as interações entre pessoas [...] (MOSCOVICI, 2003, p. 48).
\end{abstract}

Podemos citar ainda a interessante explicação de Guareschi (1995) que, baseando-se em Sperber ${ }^{9}$, ilustra a diferença entre representações sociais e representações coletivas, fazendo uma analogia com a medicina. Para esse autor, a mente humana é suscetível de representações culturais, do mesmo modo que o corpo humano é suscetível às doenças. Por isso, este diferencia as representações em: coletivas - representações duradouras, tradicionais, amplamente distribuídas, ligadas à cultura, transmitidas de geração a geração, de forma que podem ser comparadas à endemia; e sociais - típicas de culturas modernas, que se espalham rapidamente por toda a população, possuem curto período de vida, são semelhantes aos "modismos" e podem ser comparadas à epidemia. Dessa maneira, Guareschi

8 Sobre esta separação entre o individual e o coletivo, Robert M. Farr (1995) faz um estudo detalhado em seu artigo Representações sociais: a teoria e sua história, na obra Textos em Representações Sociais, organizado por Guareschi e Jovchelovitch. Farr desenvolve toda uma prehistória da Teoria das Representações Sociais.

9 SPERBER, D. Antropology and psychology: towards an epidemiology of representations. Man (New Series), 1985, p. 229-260. 
faz alusão a um elemento geográfico, delimitando o tradicional ao local regional, e o moderno ao global e que pode abranger tudo.

Segundo Farr (1995, p. 45),

Moscovici modernizou esse panteão de objetos sagrados, substituindo a magia pela ciência. A ciência é uma das forças que distingue o mundo moderno do mundo medieval. Ela é [...] uma fonte fecunda de novas representações.

Nesse mesmo sentido, Amaral (2005, p. 14), afirma que

nas sociedades contemporâneas ocidentais, pode-se afirmar que o papel dos mitos e crenças das antigas representações coletivas foi substituído pela ação dos meios de comunicação de massa das atuais representações sociais na construção da realidade. O senso comum deixa de ser constituído somente pelo mito e passa a se basear na mídia, em primeiro lugar.

Portanto, considerando uma sociedade moderna, marcada pelo pluralismo e pela rapidez das mudanças econômicas, culturais e ambientais, a expressão representações sociais seria a mais condizente com as dinâmicas próprias do mundo contemporâneo.

Como exemplo, podemos destacar o discurso científico dos problemas ambientais, que tem sido amplamente divulgado nos meios de comunicação de massa. Tal difusão tem modificado, profundamente, tanto a sua compreensão, quando em interação com os saberes tradicionais dos grupos sociais, bem como as interações deste grupo com elementos naturais, visto que estas relações tornaram-se mais reflexivas. A partir dessa difusão, os discursos ambientais foram inseridos nos saberes do cotidiano dos indivíduos ou dos grupos sociais como "verdades", passando a fazer parte do discurso no senso comum.

\section{COMO SÃO CRIADAS AS REPRESENTAÇÕES SOCIAIS?}

Compreendemos, até aqui, que as representações sociais são conhecimentos elaborados e compartilhados entre indivíduos ou grupos na sociedade moderna, através de relações interpessoais. Elas circulam, cruzam e se cristalizam incessantemente através da mídia, de uma fala, de um gesto, de um encontro e, até mesmo, de interações com o meio ambiente, em nosso universo cotidiano. Segundo Sá (1998, p. 21), os fenômenos de representação social estão "espalhados por aí", estão presentes na arte, nas crenças e nos mitos.

Dessa forma, os indivíduos são pensadores ativos, consumidores de conhecimento, inseridos em uma sociedade pensante, baseado na diversidade dos pensares. Moscovici (1978) ressalta, ainda, a existência de dois tipos de universos de conhecimento na sociedade: os universos consensuais e os universos reificados. Geograficamente, encontram-se aqui três mundos: o mundo vivido individual, o mundo social consensual e o mundo reificado.

Por universo reificado, entende-se aquele que fixa e preserva institucionalmente o conhecimento. Onde se

produzem e circulam as ciências e o pensamento erudito em geral, com sua objetividade, seu rigor lógico e metodológico, sua teorização abstrata, sua compartimentação em especialidades e sua estratificação hierárquica (SÁ, 1995, p. 28).

Assim, é considerado um universo diferente e desigual, onde não é qualquer pessoa que possui o "poder" de falar sobre determinados conhecimentos, ou seja, "a competência é determinada de acordo com o mérito atribuído e o direito de exercer determinada função [...] é um mundo com uma linguagem específica" (GIL FILHO, 2005, p. 56). A tendência é que esses universos aumentem, com o surgimento de novas formas de organização da sociedade, dando valor exagerado às informações da ciência.

As teorias científicas se encontram nesse universo do conhecimento. Elas orientam e organizam a prática científica, como um guia de conduta para abordar um problema estudado. O conhecimento científico

é construído a partir de passos formalmente delimitados (que envolvem a formulação de hipóteses, a observação e/ou experimentação do objeto de estudo, a sua validação, comprovação ou interpretação, a previsão e aplicação dos resultados) [...] (SANTOS, 2005, p. 20-21).

Já o universo consensual, é onde circulam as teorias do senso comum e as interações que se dão entre pessoas comuns. Poucos integrantes desse universo possuem uma competência reconhecida sobre o tema discutido, "não conhecem limites especializados, obedecem a uma outra lógica, chamada de 'lógica natural', 
utilizam mecanismos diferentes de 'verificação'” (SÁ, 1995, p. 28-29). São "amadores", curiosos, leigos que, através de práticas interativas cotidianas, compartilham ideias e interpretações do mundo, produzindo as suas próprias representações sociais.

Os universos consensuais, como realça Moscovici (2003, p. 54-55), "são locais onde todos querem sentir-se em casa, a salvo de qualquer risco, atrito ou conflito [...] onde os objetos, pessoas e acontecimentos são percebidos e compreendidos em relação a prévios encontros e paradigmas". Como já mencionado anteriormente, esses dois universos de conhecimento se completam, apesar de tão diferentes entre si.

Considerando a sociedade atual, marcada pela velocidade, pela hegemonia do saber científico e pelo capitalismo (este também desenvolvido através de reflexões científicas), o novo surge a cada instante como teorias ou descobertas científicas, invenções e desenvolvimentos técnicos, reorganizações sociais e ambientais, decisões políticas, entre outros -, o que faz gerar perguntas, que necessitam de respostas no senso comum. Percebe-se, nesse momento, que o discurso hegemônico se expressa em formas específicas de circulação restrita ao universo acadêmico, como livros, artigos, conferências, que parecem muito distantes para o mundo comum, principalmente devido a sua linguagem técnica. Deduzimos que, ao mesmo tempo em que este novo, estranho ou o "não familiar", -expressão usada por Moscovici (1978)-, fascina a todos numa sociedade, onde, por questões do sistema educativo, a atitude de venerar a ciência (sem verdadeiramente participar nela) aguça a curiosidade, ela (a ciência) também torna-se problemática.

Portanto, quando as pessoas falam, argumentam, discutem no cotidiano à presença de um fenômeno científico, ou não, estão procurando respostas a algo considerado estranho. Situação semelhante quando os indivíduos ficam expostos às instituições, aos meios de comunicação, aos mitos e à herança histórico-cultural de suas sociedades, ou a problemas ambientais. É a partir desta exposição e da busca por construir respostas, que se orienta a vida prática, e que as representações sociais são formadas (GUARESCHI, 1995, p. 20).

As pessoas assimilam e se familiarizam com o conhecimento não familiar, assim, este passa a ser compartilhado, absorvido, trabalhado e articulado, nos mais diversos lugares, nas ruas, bares, parques, no local de trabalho, nas casas, tornando-se, dessa maneira, próprio e familiar. Como argumenta Moscovici (1978, p. 53),
[...] o conhecimento penetra no "mundo da conversação", prosseguindo as permutas verbais depois de certo tempo. Uma frase, um enigma, uma teoria, apanhados no ar, aguçam a curiosidade, prendem a atenção. Fragmentos de diálogo, leituras descontínuas, expressões ouvidas algures retornam ao espírito dos interlocutores, misturam-se às suas impressões; brotam as recordações, as experiências comuns apossam-se delas. Graças a esses falatórios, não só as informações são transmitidas e os hábitos do grupo confirmados, mas cada um adquire uma competência enciclopédica acerca do que é objeto da discussão. À medida que a conversa coletiva progride, a elocução regulariza-se, as expressões ganham em precisão. As atitudes ordenam-se, os valores tomam seus lugares, a sociedade começa a ser habitada por novas frases e visões. E cada um fica ávido por transmitir o seu saber e conservar um lugar no círculo de atenção que rodeia aqueles que "estão ao corrente", cada um documentase aqui e ali para continuar "no páreo".

Cabe lembrar aqui que o não familiar, que circula nesse universo reificado, não se origina apenas na ciência, mas também em outras instituições do saber, como nas religiões, por exemplo. Contudo, sempre precisa de mediação para chegar num ambiente consensual. Esta pode resultar dos próprios esforços da população dita "leiga", mas também de outros divulgadores - como a igreja, artistas, políticos e, principalmente, os meios de comunicação de massa. Todos estes dispõem de sistemas de conhecimentos mais abrangentes, que passam a fazer parte do nosso cotidiano através de reduções. Nesta interface, operam os processos pelos quais o conhecimento reificado passa a ser familiar. Moscovici (1978, p. 20) argumenta que:

\footnotetext{
[...] o propósito de todas as representações é tornar algo não-familiar, ou a própria não-familiaridade, familiar [...]. A familiarização é sempre um processo construtivo de ancoragem e objetivação [...] através do qual o não-familiar passa a ocupar um lugar dentro de nosso mundo familiar.
}

Desta maneira, os processos de ancoragem e objetivação são fundamentais para a estruturação das representações sociais. Por exemplo, os problemas ambientais, tornam-se uma representação social, quando passam a ser sentidos, seja no discurso ou na realidade. Assim, passam a ser uma preocupação e começam a ser percebidos e discutidos, no mundo do 
senso comum.

Neste âmbito, a objetivação é o mecanismo que procura "transformar algo abstrato em algo quase concreto, transferir o que está na mente em algo que exista no mundo físico" objetivando-o. A ancoragem é o mecanismo que "tenta ancorar ideias estranhas, reduzilas a categorias e imagens comuns, colocá-las em um contexto familiar" (MOSCOVICI, 2003, p. 60-61). Assim, também a reificação científica inclui-se nos saberes e discursos populares.

Como vimos anteriormente, o estranho e o diferente são vistos muitas vezes como "ameaçador", a ancoragem nos ajuda a conter tais circunstâncias. Por isso, este processo é fundamental em nossa vida cotidiana, pois nos auxilia a enfrentar as dificuldades de compreensão ou conceituação de determinados fenômenos hegemônicos e estabelecer uma relação positiva ou negativa com tal objeto. "Ancorar é, pois, classificar e dar nome a alguma coisa. Coisas que não são classificadas e que não possuem nome são estranhas, não existentes e ao mesmo tempo ameaçadoras" (MOSCOVICl, 2003, p. 61).

A ancoragem e a objetivação também são maneiras de lidar com a memória, permitindo que o não familiar do passado, como forma específica de conhecimento, passe a ocupar um lugar dentro do nosso mundo familiar. Nesse sentido, a ancoragem mantém a memória em movimento e a memória é dirigida para dentro, sempre absorvendo e descartando objetos, pessoas e acontecimentos, que ela classifica com um nome e de acordo com um tipo. A objetivação é transformar uma abstração em algo quase físico (MOSCOVICl, 2003).

Com efeito, uma representação social é a organização de imagens e linguagens de vários ambientes exteriores. Não se refere apenas ao ambiente da ciência, mas a qualquer sistema de conhecimento ou expressão provindo da mídia, da tradição, das leis políticas e até mesmo do ambiente urbano. Todos estes adicionam elementos de saberes diferentes, em nossa vida cotidiana, ao que já é comum e, consequentemente, neste processo de comunicação, todos se modificam. Assim, a representação social, formada sobre determinado fenômeno, assunto, ou até mesmo um objeto material, encontra-se em contínua elaboração, sempre sendo ligada a um determinado contexto histórico e geográfico, dentro das atividades cotidianas, tanto sociais, culturais, econômicas e ambientais.

\section{REPRESENTAÇÕES SOCIAIS E MEIO AMBIENTE: UMA PROPOSIÇÃO DE PESQUISA}

Em síntese, a Teoria das Representações Sociais refere-se a "um modelo teórico, um conhecimento científico que visa compreender e explicar a construção [do] conhecimento leigo, [os saberes] do senso comum" (SANTOS, 2005, p. 21).

Segundo a teoria, as representações sociais são criadas sobre determinados fenômenos se estes estiverem expostos nas mídias e conversações particulares. Isso nos dá segurança para afirmarmos que os problemas ambientais geram representações sociais, visto que, encontram-se amplamente divulgados nos meios de comunicação de massa. Exemplificando podemos citar o atual alarde em torno de um possível "aquecimento global", suas causas e as formas como cada cidadão, em particular, pode contribuir para diminuir esse problema ambiental. Da mesma forma, a "crise da água", "guerra pela água", "escassez da água", são temas recorrentes nos noticiários e programas jornalísticos; de forma que os problemas ambientais de mundos geograficamente distantes são incorporados ao nosso cotidiano, passando a fazer parte do discurso no senso comum.

Segundo Fèlonneau (2003) é importante entender essas representações sociais para compreender e explicar a realidade ambiental. Elas nos ajudam a melhor entender e, às vezes, até mesmo prever, as condutas individuais e sociais em relação ao meio que envolve o grupo social. Segundo essa autora, pela análise das representações sociais, podemos verificar se os sujeitos possuem representações negativas ou positivas, em relação ao meio ambiente. A partir daí, podemos entender as condutas de preservação e até mesmo de agressão em relação ao meio.

Nesse sentido, uma pauta possível de estudos em representações sociais do meio ambiente poderia ser um questionamento sobre o papel de que imagens e discursos que apresentam problemas ambientais em escala global, ou de outras regiões geográficas, interferem nas visões e atitudes das pessoas localizadas e nas relações que estabelecem com o ambiente próximo. Um estudo desta natureza poderia nos mostrar o quanto, no mundo contemporâneo, os aspectos simbólicos que entram na constituição dos ambientes, tal como definiu Fèlonneau (2003), são resultado de interconexões que se processam em múltiplas escalas geográficas. 
FAGUNDES, B. A teoria das representações sociais nos estudos ambientais

\section{REFERÊNCIAS}

ALEXANDRE, M. Representação Social: uma genealogia do conceito. Revista Comum, Rio de Janeiro, RJ. v. 10, n. 23, p. 122-138, julh/dez. 2004. Disponível em: <http://www.facha. edu.br/publicações/comum/comum23/artigo7.pdf> . Acesso em: 4/10/2006.

AMARAL, R. M. do. Representações sociais e discurso midiático: como os meios de comunicação de massa fabricam a realidade. Revista Lâmina, Pernambuco, n. 1, set. 2005. Disponível em: <http://www.ppgcomufpe.com.br/lamina/artigorenata.pdf>. Acesso em: 27/8/2006.

ARRUDA, A. Ecologia e desenvolvimento: representações de especialistas em formação. In: SPINK, M. J. (Org.). O conhecimento no cotidiano: As representações sociais na perspectiva da psicologia social. São Paulo: Brasiliense, 1995. p. 234-265.

BAUER, M. A popularização da ciência como imunização cultural: a função de resistência das representações sociais. In: GUARESCHI, P. ; JOVCHELOVITCH, S. (Org.). Textos em representação social. Petrópolis, RJ: Vozes, 1995. p. 229-255.

FAGUNDES, B. A água urbana: representações sociais na cidade. In: $1^{\circ}$ Colóquio Nacional do NEER. Espaço e representações: reconstruções teóricas do geográfico. Curitiba: UFPR, 2006 (nov). CD ROOM não paginado.

FARR, R. M. Representações sociais: a teoria e sua história. In: GUARESCH, P. ; JOVCHELOVITCH, S. (Org.). Textos em representação social. Petrópolis, RJ: Vozes, 1995. p. 31-59.

FÉLONNEAU, M. Les représentations sociales dans le champ de l'environnement. In: MOSER, G.; WEISS, K. (Org.) Espaces de vie: aspects de la relation homme-environnement. Paris: Armand Colin, 2003. p. 145-176.

FREITAS, E. S. de. Representações sociais, meio ambiente e saúde: por uma educação ambiental de qualidade. Revista: O mundo da saúde. São Paulo, v. 30, n. 4, p. 598-606, out/ dez, 2006.

GIL FILHO, S. F. Geografia Cultural: Estrutura e Primado das Representações. Revista Espaço e Cultura. Rio de Janeiro: UERJ, n. 3, p. 51-58, 2005 (dez).

GUARESCHI, P. Sem dinheiro não há salvação: ancorando o bem e o mal entre os neopentecostais. In: GUARESCHI, P.; JOVCHELOVITCH, S. (Org.). Textos em representação social. Petrópolis, RJ: Vozes, 1995. p. 191-225.

JODELET, D. Loucuras e representações sociais. Petrópolis, RJ: Ed. Vozes, 2005. 398 p.
JODELET, D. Representações sociais: um domínio em expansão. In: . (Org.). As Representações Sociais. Rio de Janeiro, RJ: EdUERJ, 2001. p. 17-44.

JOVCHELOVITCH, S. Representações Sociais e esfera pública: A construção simbólica dos espaços públicos no Brasil. Petrópolis, RJ: Vozes, 2000. p. 11-42.

LANE, S. T. M. Usos e abusos do conceito de Representação Social. In: SPINK, M. J. (Org.). O conhecimento no cotidiano: As representações sociais na perspectiva da psicologia social. São Paulo: Brasiliense, 1995. p. 58-72.

MENDONÇA, F. Geografia socioambiental. In: MENDONÇA, F.; KOZEL, S. (Org.) Elementos de Epistemologia da Geografia Contemporânea. Curitiba: Editora UFPR, p. 121-143, 2002.

MOSCOVICI, S. A representação social da psicanálise. Rio de Janeiro: Zahar, 1978. 291 p.

MOSCOVICI, S. Representações sociais: investigações em psicologia social. Petrópolis, RJ: Vozes, 2003. 404 p.

OLIVEIRA, F. O. de.; WERBA, G. C. Representações Sociais. In: JACQUES, M. da G. C. et al. Psicologia Social Contemporânea. 9 ed. Petrópolis: Editora Vozes. 2005. p. 104-117.

SÁ, C. P. de. A construção do objeto de pesquisa em Representações Sociais. Rio de Janeiro: EdUERJ, 1998. $110 p$.

SÁ, C. P. de. Representações Sociais: o conceito e o estado atual da teoria. In: SPINK, M. J. (Org.). O conhecimento no cotidiano: As representações sociais na perspectiva da psicologia social. São Paulo: Brasiliense, 1995. p. 19-45.

SANTOS, M. de F. de S. A Teoria das Representações Sociais. In: SANTOS, M. de F. de S.; ALMEIDA, L. M. de. (Org.). Diálogos com a Teoria das Representações Sociais. Pernambuco: Ed Universitária da UFPE, 2005. p. 15-38.

SAWAIA, B. B. Representação e ideologia - o encontro desfetichizador. In: SPINK, M. J. (Org.). O conhecimento no cotidiano: As representações sociais na perspectiva da psicologia social. São Paulo: Brasiliense, 1995. p. 73-84.

SCHIELE, B.; BOUCHER, L. A exposição científica: uma maneira de representar a ciência. In: JODELET, D. (Org.). As Representações Sociais. Rio de Janeiro, RJ: EdUERJ, 2001. p. 363-378.

SPINK, M. J. P. O estudo empírico das Representações Sociais. In: SPINK, M. J. (Org.). O conhecimento no cotidiano: As representações sociais na perspectiva da psicologia social. São Paulo: Brasiliense, 1995. p. 85-108. 
